\title{
The Effect of Misophonia on the Severity of Depression and Anxiety in Multiple Sclerosis
}

\author{
Multipl Sklerozda Mizofoni Varlı̆̆ının Depresyon ve Anksiyete Şiddeti Üzerine Etkisi
}

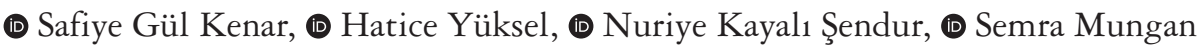

Ankara City Hospital, Clinic of Neurology, Ankara, Turkey

\begin{abstract}
Objective: Depression and anxiety are common and well defined psychiatric comorbidities in multiple sclerosis (MS), which decrease the quality of life. Misophonia is an underrecognized condition that consists of abnormal emotional responses to specific environmental sounds or rarely to images. Limbic system impairments can be the leading cause of both psychiatric disorders in MS and misophonia. The prevalence of misophonia and its relationship with depression and anxiety have not been studied in the MS population. This study aimed to investigate the frequency of misophonia in MS and its effects on depression and anxiety severity. A secondary aim was to evaluate the effect of the factors associated with MS on the misophonia severity.

Materials and Methods: Fifty-nine patients with MS were recruited for the study. MS type, disease duration, attack frequency per year and smoking habbits were evaluated. The presence and severity of misophonia, and depression and anxiety scores in MS group were compared with 63 healthy controls.

Results: The frequency of misophonia was significantly higher in MS group (37.3\%) compared to controls (19.4\%) (p=0.046). Severe depression (23.7\%) and anxiety $(28.8 \%)$ were more frequent in the MS group compared to controls (1.6\% and $11.1 \% \mathrm{p}<0.001)$. Patients with MS and misophonia (MSwM) had a significantly higher frequency of severe depression $(\mathrm{p}=0.004)$ and anxiety $(\mathrm{p}=0.019)$ than patients with MS without misophonia (MSwoM). MS type, duration, attack frequency and smoking habbits were comparable between MSwM and MSwoM. There was a significant positive correlation between the misophonia score and the Beck depression score ( $\mathrm{p}=0.029)$ in patients with MS.
\end{abstract}

Conclusion: Misophonia is frequent in the MS population and increases the severity of depression and anxiety.

Keywords: Multiple sclerosis, misophonia, depression, anxiety

Öz

Amaç: Depresyon ve anksiyete multipl skleroz (MS) hastalarında yaşam kalitesini düşüren, yaygın görülen ve iyi tanımlanmış komorbiditelerdir. Mizofoni, genellikle belirli çevresel seslere veya nadiren de görsel uyaranlara karşı anormal duygusal tepkiler oluşmasına sebep olan ve hala yeteri kadar farkedilmeyen bir durumdur. Limbik sistem bozukluklarının, hem MS'deki psikiyatrik bozuklukların hem de mizofoninin patofizyolojisinde sorumlu olabileceği düşünülmektedir. Mizofoni prevalansı, depresyon ve anksiyete ile ilişkisi MS popülasyonunda incelenmemiştir. Bu çalışmanın amacı MS'de mizofoni sıklığını ve bunun depresyon ve anksiyete şiddetine etkilerini araştırmaktır. İkincil amaç, MS ile ilişkili faktörlerin mizofoni şiddeti üzerindeki etkisini değerlendirmektir.

Gereç ve Yöntem: Elli dokuz MS hastası çalışmaya dahil edildi. MS tipi, hastalık süresi, yıllık atak sıklığı ve sigara içme alışkanlıkları değerlendirildi. MS grubunda mizofoni, depresyon ve anksiyete varlı̆̆ı ve şiddeti 63 sağlıklı kontrol ile karşılaştırıldı.

Bulgular: Mizofoni sıklığı MS grubunda $(\% 37,3)$ kontrollere $(\% 19,4)$ göre anlamlı olarak daha yüksekti $(\mathrm{p}=0,046)$. MS grubunda şiddetli depresyon $(\% 23,7)$ ve anksiyete $(\% 28,8)$ kontrollere göre $(\% 1,6$ ve $\% 11,1 \mathrm{p}<0,001)$ daha s1kt1. Mizofoni olan MS (MSwM) grubu, mizofoni olmayan MS (MSwoM) grubu ile karşılaştırıldığında şiddetli depresyon $(\mathrm{p}=0,004)$ ve anksiyete $(\mathrm{p}=0,019)$ anlamlı olarak daha sıktı. MS tipi, süresi, atak sıklığı ve sigara içme alışkanlıkları MSwM ve MSwoM arasında benzerdi. MS'de mizofoni puanı ile Beck depresyon puanı ( $\mathrm{p}=0,029)$ arasında anlamlı pozitif korelasyon vardı.

Sonuç: Misofoni MS popülasyonunda sık karşılaşılan bir komorbidite olup depresyon ve anksiyete şiddetini arttırabilmektedir.

Anahtar Kelimeler: Multipl skleroz, mizofoni, depresyon, anksiyete

\section{Introduction}

Multiple sclerosis (MS) is a chronic demyelinating disease of the central nervous system. It affects young people at their productive ages and is more common in females. Although psychiatric comorbidities often accompany MS, they are underestimated and overlooked in clinical settings.

Address for Correspondence/Yazışma Adresi: Safiye Gül Kenar MD, Ankara City Hospital, Clinic of Neurology, Ankara, Turkey Phone: +90 5374352503 E-mail: safiyegulkenar@hotmail.com ORCID: orcid.org/0000-0003-2458-3813

Received/Gelis Tarihi: 29.09.2021 Accepted/Kabul Tarihi: 09.01.2022

${ }^{\circ}$ Copyright 2022 by Turkish Neurological Society

Turkish Journal of Neurology published by Galenos Publishing House. 
Depression is three times more common in patients with MS, and lifelong prevalence is almost $50 \%$. Genetic features and comorbid diseases have been shown to be the factors increasing the risk for developing depression in patients with MS (1). Functional magnetic resonance imaging (MRI) studies performed in patients with MS have shown impairment in regional activity of limbic system and in functional conduction patterns, especially in the presence of depression (2). Anxiety disorder is the second most common comorbidity, occurring in more than one-third of patients and affecting females mostly. It is significantly associated with disability (3).

Misophonia, which is known as hypersensitivity to the sounds in the surrounding environment, is frequently encountered in daily life. Patients with misophonia react psychologically and physically to recurrent auditory or visual stimuli with a variety of characteristics. The most common reactions are anger and disgust, increased heart rate, and muscle contraction. Different coping mechanisms can be used in order to avoid these disturbing symptoms. The most preferred methods include moving away from such environment, suppressing the trigger sound if it cannot be removed, or acting incompatible with the environment or warning the sound source. These behavioral patterns, combined with the patient's anxiety, adversely affect the quality of daily life. There is been an increasing awareness of misophonia over the last decade, but it is still unclear whether it is a psychiatric disease.

Although the frequency of misophonia in the general population was unknown, two different studies reported frequency rates of $20 \%$ and $17 \%$ in university students $(4,5)$. Pathophysiology of misophonia has not been fully clarified. Functional neuroimaging studies found increased activity in the right insula, right anterior cingulate cortex, and right superior temporal cortex after exposure to the misophonic trigger (6).

The severity of misophonia findings is associated with concomitant anxiety (7). It is suggested that the severity of misophonia decreases in the absence of comorbid psychiatric disorders (8).

To our knowledge, this study is the first to evaluate the relationship between MS and misophonia. We assumed that misophonia might be more common in patients with MS through shared pathophysiological mechanisms such as the limbic system alterations. We also investigated whether the presence of misophonia aggravated the severity of depression and anxiety in patients with MS.

\section{Materials and Methods}

\section{Study Design and Procedures}

This study was a prospective case-control study. Fifty-nine MS patients who presented to MS outpatient clinic and volunteered to answer the questionnaires were included in the study. After the patients were informed about misophonia, those with misophonic complaints that met Schröder's et al. (9) diagnostic criteria were considered as misophonia positive.

\section{According to the criteria set;}

1. Specific stimuli provoke an impulsive physical reaction.

2. Anger drives a profound sense of loss of self-control.

3. Person recognizes that these feelings are excessive, unreasonable, or out of proportion to the circumstances.
4. Person tends to avoid misophonic stimulus. If they cannot avoid it, they endure encounters with intense discomfort, anger or disgust.

5. Person's anger, disgust, or avoidance causes significant interference in daily life.

6. Another condition does not better explain the person's anger, disgust, or avoidance.

The A-miso-S scale is a 7-item self-report measure that assesses the length of time in which the person is affected by such sounds, the extent of problems they have in daily life, the stress degree associated with the sounds, the amount of effort shown by the sufferer to resist thinking about the sounds, the ability of control over their thoughts and avoidance of the stimuli. This scale is an adapted version of the Yale-Brown obsessive-compulsive scale (9). Scores are categorized under five groups: A score of 0-4 indicates subclinical, 5-9 mild, 10-14 moderate, 15-19 severe, and 20-24 extreme symptoms. The scale was translated into Turkish by the authors but was not validated in the Turkish language.

Beck depression inventory (BDI) and Beck anxiety inventory (BAI) were administered to all patients with MS. Their most upto-date hospital laboratory values were examined in the last year, and hemoglobin, ferritin, vitamin B12, vitamin D, folic acid, and thyroid-stimulating hormone values were recorded. Type and duration of MS, disease-modifying therapies used in MS treatment, presence of attacks in the last year and smoking habits were noted.

BDI, BAI, and A-miso-S test in the presence of misophonia were performed on control group.

\section{Study Population}

All patients met the 2017 McDonald criteria. Patients with severe cognitive impairment and aphasia were not included to the study. None of the patients had hearing loss or tinnitus complaints. Control group consisted of 63 age- and sex-matched healthy individuals who had no diagnosed neurological disorder. Ankara City Hospital Institutional Review Board/Ethics Committee approved the study protocol (protocol number: E1-20-1315). The protocol conformed to Good Clinical Practice Quidelines and Declaration of Helsinki principles. Informed consent forms were obtained from all patients and controls.

\section{Statistical Analysis}

Data were analyzed with IBM SPSS V23. Compliance with normal distribution was examined with Kolmogorov-Smirnov or Shapiro-Wilk tests. Independent samples t-test was used to compare normally distributed data, and results were presented as mean \pm standard deviation. Mann-Whitney $U$ test was used to compare data that did not show normal distribution, and the results were given as median (minimum-maximum). The chi-square test was used for the comparison of categorical data. Categorical data were presented as frequency (percentage). Pearson's correlation analysis was used to test the correlation between misophonia score and clinical parameters including BDI score, BAI score, duration of MS and patient's age. Binary logistic regression analysis was performed to detect independent factors associated with misophonia.

Since there was no similar study in the literature, a pilot study was conducted, and 20 participants in each of the experimental and control groups were included in the study. Power analysis was performed on the obtained values. 
For the misophonia, according to $95 \%$ confidence (1- $\alpha$ ), $95 \%$ test power (1- $\beta$ ) and w: 0.482 effect size, a minimum of 56 individuals should be included in the study. The study was completed on 119 participants, and the power of the test was $99.9 \%$ in the post-hoc power analysis.

For the BDI score, according to $95 \%$ confidence (1- $\alpha)$, 95\% test power (1- $\beta$ ), d: 1.316 effect size and Two-Way hypothesis, 34 participants, including a minimum of 17 participants in each group, should be included in the study. The study was completed on 119 participants and the power of the test was $99.9 \%$ in the posthoc power analysis.

For the BAI score, according to $95 \%$ confidence $(1-\alpha), 95 \%$ test power (1- $\beta)$, d: 1.596 effect size and Two-Way hypothesis, 24 participants, including 12 participants in each group, should be included in the study. The study was completed on 119 participants, and the power of the test was obtained as $100 \%$ in the posthoc power analysis. A p value $<0.05$ was considered statistically significant.

\section{Results}

Age, sex, and smoking status were similar in both MS and control groups $(\mathrm{p}=0.605, \mathrm{p}=0.965$ and $\mathrm{p}=0.843$, respectively). $\mathrm{BDI}$ and BAI scores in the MS group were significantly higher than the control group $(\mathrm{p}=0.028, \mathrm{p}=0.001$, and $\mathrm{p}=0.001$, respectively). Misophonia score was comparable within both groups $(\mathrm{p}=0.486)$ (Table 1).

Nevertheless, the frequency of misophonia was significantly higher in the MS group (37.3\%) compared to controls (19.4\%) $(p=0.046)$. While $23.7 \%$ of the MS group had severe depression, this rate was $1.6 \%$ in the control group $(\mathrm{p}<0.001)$. The level of anxiety also varied by group ( $\mathrm{p}<0.001$ ) with $28.8 \%$ of the patients in the MS group and $11.1 \%$ in the control group showing severe anxiety (Table 2).

Age, sex, smoking, duration of MS, presence of MS attacks, and type of MS were similar in both patients with MS and misophonia (MSwM) and without misophonia (MSwoM) (Table 3).

The MSwM and MSwoM groups had comparable laboratory test results $(p>0.050)$, but incomparable BDI and BAI scores. The median score of BDI was 25 in the MSwM group versus 12 in the MSwoM group ( $\mathrm{p}=0.002)$, whereas the median score of BAI

Table 1. Comparison of the demographic and clinical data of the MS group and control group

\begin{tabular}{|c|c|c|c|}
\hline & MS n=59 & $\begin{array}{l}\text { Control } \\
\mathrm{n}=63\end{array}$ & $\mathrm{p}$ \\
\hline Age (year) & $32.4 \pm 9.8$ & $33.3 \pm 9.7$ & $0.605^{*}$ \\
\hline $\begin{array}{l}\text { Sex } \\
\text { Female } \\
\text { Male }\end{array}$ & $\begin{array}{l}44(69.5) \\
19(30.5)\end{array}$ & $\begin{array}{l}41(69.8) \\
18(30.2)\end{array}$ & $0.967^{*}$ \\
\hline $\begin{array}{l}\text { Smoking } \\
\text { Present } \\
\text { Absent }\end{array}$ & $\begin{array}{l}14(23.7) \\
45(76.3)\end{array}$ & $\begin{array}{l}14(22.2) \\
49(77.8)\end{array}$ & $0.843^{* *}$ \\
\hline Misophonia score & $11.1 \pm 4$ & $10.0 \pm 4.3$ & $0.486^{* * *}$ \\
\hline BDI score & $18.7 \pm 11.8$ & $11.2 \pm 6.3$ & $0.001 * *$ \\
\hline BAI score & $20.1 \pm 13.4$ & $10.6 \pm 9.5$ & $0.001 * *$ \\
\hline
\end{tabular}

Table 2. Comparison of control and MS groups

\begin{tabular}{llllll} 
& $\begin{array}{l}\text { Control } \\
(\mathbf{n}=63)\end{array}$ & $\begin{array}{l}\text { MS } \\
(\mathbf{n}=59)\end{array}$ & $\begin{array}{l}\text { Total } \\
(\mathbf{n}=122)\end{array}$ & $\begin{array}{l}\text { Test } \\
\text { statistics }\end{array}$ & $\mathrm{p}$ \\
\hline $\begin{array}{l}\text { Misophonia } \\
\text { Absent }\end{array}$ 50(80.6) & $37(62.7)$ & $87(71.9)$ & $\mathrm{X}^{2}: 3.966$ & 0.046 \\
Present & 12 & 22 & 34 & & \\
Depression & & & & \\
Minimal & $29(46)$ & $15(25.4)$ & $44(36.1)$ & & \\
Mild & 25 & 15 & 40 & $\mathrm{X}^{2}: 20.242$ & $<0.001$ \\
Moderate & 8 & 15 & 23 & & \\
Severe & 1 & 14 & 15 & & \\
Anxiety & & & & & \\
Minimal & 33 & 10 & 43 & & \\
Mild & $23(36.5)$ & $32(54.2)$ & $55(45.1)$ & $X^{2}: 18.613$ & $<0.001$ \\
Severe & $7(11.1)$ & $17(28.8)$ & $24(19.7)$ & & \\
\hline
\end{tabular}

$\mathrm{X}^{2}$ : Chi-square test statistics, MS: Multiple sclerosis

Table 3. Comparison of the demographic and clinic data of the MSwM and MSwoM groups

\begin{tabular}{|c|c|c|c|}
\hline & MSwM n = 22 & $\begin{array}{l}\text { MSwoM } \\
\mathrm{n}=37\end{array}$ & $\mathrm{p}$ \\
\hline Age (years) & $30.50 \pm 9.39$ & $33.94 \pm 9.88$ & 0.084 \\
\hline \multicolumn{4}{|l|}{ Sex } \\
\hline Female & $13(59.1 \%)$ & $28(75.7 \%)$ & \multirow{2}{*}{0.244} \\
\hline Male & $9(40.9 \%)$ & $9(24.3 \%)$ & \\
\hline \multicolumn{4}{|l|}{ Smoking } \\
\hline Present & $5(22.7 \%)$ & $9(24.3 \%)$ & \multirow{2}{*}{0.889} \\
\hline Absent & $17(77.3 \%)$ & $28(75.7 \%)$ & \\
\hline MS duration & $4.83 \pm 4.45$ & $5.82 \pm 4.24$ & 0.417 \\
\hline \multicolumn{4}{|c|}{ MS attack (within last year) } \\
\hline Present & $13(59.1 \%)$ & $17(45.9 \%)$ & \multirow{2}{*}{0.329} \\
\hline Absent & $9(40.9 \%)$ & $20(54.1 \%)$ & \\
\hline \multicolumn{4}{|l|}{ MS type } \\
\hline RRMS & $19(86.4 \%)$ & $33(89.2 \%)$ & \multirow{4}{*}{0.368} \\
\hline PPMS & - & $2(5.4 \%)$ & \\
\hline SPMS & $2(9.1 \%)$ & $2(5.4 \%)$ & \\
\hline PRMS & $1(4.5 \%)$ & - & \\
\hline
\end{tabular}

${ }^{*}$ Chi-square test, MS: Multiple sclerosis, MSwM: Patients with MS and misophonia, MSwoM: Patients with MS without misophonia, RRMS: Relapsingremitting multiple sclerosis, PPMS: Primary progressive multiple sclerosis, SPMS: Secondary progressive multiple sclerosis, PRMS: Progressive relapsing multiple sclerosis

was 27.5 in the MSwM group versus 13 in the MSwoM group $(\mathrm{p}=0.003)$ (Table 4).

In binary logistic regression analysis, BDI score was determined as an independent risk factor for misophonia in patients with MS (Table 5).

There was a significant positive correlation between the misophonia score and BDI score in the MS group (r: 0.466, $\mathrm{p}=0.029$ ) (Figure 1). However, such correlation couldn't be achieved with the BAI score ( $\mathrm{r}: 0.348, \mathrm{p}=0.112)$, duration of MS $(\mathrm{r}:-0.298, \mathrm{p}=0.178)$, and age $(\mathrm{r}:-0.305, \mathrm{p}=0.168)$ (Figure 2$)$.

The frequency of severe depression and severe anxiety was significantly higher in the MSwM group ( $\mathrm{p}=0.004, \mathrm{p}=0.019$, respectively) (Table 6). 
Table 4. Comparison of laboratory values, Beck depression inventory and Beck anxiety inventory scores between MSwM and MSwoM

\begin{tabular}{|c|c|c|c|c|c|c|}
\hline & \multicolumn{2}{|c|}{ MSwM $(n=22)$} & \multicolumn{2}{|c|}{ MSwoM $(n=37)$} & \multirow{2}{*}{$\begin{array}{l}\text { Test statistics } \\
\mathrm{t}:-1.866\end{array}$} & \multirow{2}{*}{$\begin{array}{l}\mathrm{p} \\
0.064\end{array}$} \\
\hline B12 & $310 \pm 80.8$ & $280(228-544)$ & $364.8 \pm 120.5$ & $360.5(132-701)$ & & \\
\hline Vitamin D & $17.7 \pm 6.5$ & $18(8-32)$ & $19.2 \pm 12.4$ & $16(5-61)$ & U: 329.0 & 0.818 \\
\hline TSH & $1.9 \pm 1.2$ & $1.7(0.8-5.1)$ & $2.1 \pm 1.3$ & $1.8(0.3-5.3)$ & $\mathrm{U}: 377.5$ & 0.630 \\
\hline Ferritin & $31.4 \pm 38.1$ & $22(2-166)$ & $49.7 \pm 58.1$ & $26(0.5-237)$ & U: 280.5 & 0.385 \\
\hline BDI score & $25 \pm 10.2$ & $25(4-41)$ & $15.1 \pm 11.3$ & $12(1-40)$ & U: 206.5 & 0.002 \\
\hline BAI score & $27.1 \pm 13.7$ & $27.5(7-47)$ & $16 \pm 11.7$ & $13(1-43)$ & $\mathrm{U}: 220.0$ & 0.003 \\
\hline
\end{tabular}

Table 5. Independent factors associated with misophonia in binary logistic regression analysis

\begin{tabular}{llll} 
& \multicolumn{3}{l}{ Misophonia } \\
& $\mathrm{p}$ & $\operatorname{Exp}(\mathrm{B})$ & $95 \% \mathrm{CI}$ \\
\hline BDI score & 0.018 & 1.076 & $1.013-1.144$ \\
BAI score & 0.729 & 1.008 & $0.962-1.057$ \\
MS duration & 0.584 & 1.308 & $0.500-3.424$ \\
Age & 0.310 & 0.976 & $0.931-1.023$
\end{tabular}

BDI: Beck depression inventory, BAI: Beck anxiety inventory, CI: Confidence interval, MS: Multiple sclerosis

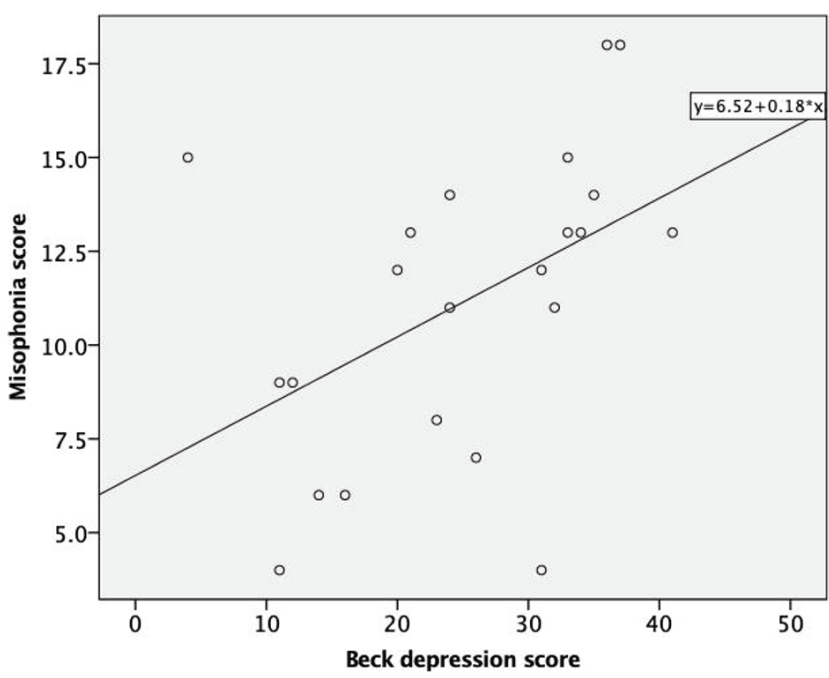

Figure 1. Correlations between misophonia score and Beck depression inventory score in MS group

MS: Multiple sclerosis

\section{Discussion}

In this cross-sectional study, misophonia (37.3\%) was more common in patients with MS $(\mathrm{p}=0.046)$. Severe depression $(23.7 \%)$ and anxiety $(28.8 \%)$ were also significantly higher in patients with MS $(\mathrm{p}<0.001)$. There was a positive correlation between misophonia score and BDS. The MSwM group had higher depression and anxiety scores compared to the MSwoM group.

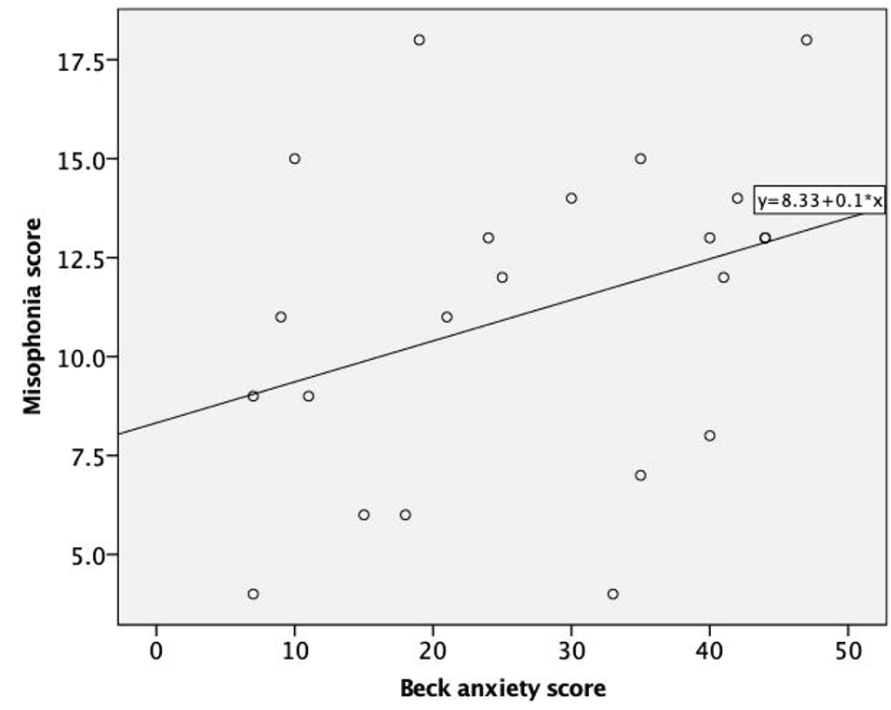

Figure 2. Correlations between misophonia score and Beck anxiety inventory score in MS group MS: Multiple sclerosis

Depression and anxiety are psychiatric impairments that cause discrete results in the MS population. Disruption in treatment compliance, diminished quality of life, and increased severity of neurologic disability are the significant consequences of psychiatric comorbidities (10). Several studies confirmed an increased frequency of depression and anxiety in patients with MS (3,11,12). In our study, frequencies of severe depression and severe anxiety were higher in the MS group, which was in good agreement with the literature.

Misophonia is described as "hatred of sound" and aggravated with every day sounds like eating, chewing, and breathing and was first described in 2002 by Jastreboff and Jastreboff (13), who worked on patients with tinnitus. People who suffer from this condition are merely aware of the fact that this is a medical problem and that they can seek help. There has been a growing interest in misophonia, especially in the last decade. Patients react both psychologically and physically to repetitive sounds with different characteristics, with the most common reactions being anger and disgust, increased heart rate, and muscle contraction. These 
Table 6. Comparison of depression and anxiety severity between MSwM and MSwoM

\begin{tabular}{|c|c|c|c|c|c|}
\hline & MSwM $(n=22)$ & MSwoM (n=37) & Total $(\mathrm{n}=59)$ & $\begin{array}{l}\text { Test } \\
\text { statistics }\end{array}$ & $\mathrm{p}$ \\
\hline \multicolumn{6}{|c|}{ Depression (\%) } \\
\hline Minimal & $1(4.5)$ & $14(37.8)$ & $15(25.4)$ & \multirow{4}{*}{$X^{2}: 13.141$} & \multirow{4}{*}{0.004} \\
\hline Mild & $5(22.7)$ & $10(27)$ & $15(25.4)$ & & \\
\hline Moderate & $6(27.3)$ & $9(24.3)$ & $15(25.4)$ & & \\
\hline Severe & $10(45.5)$ & $4(10.8)$ & $14(23.7)$ & & \\
\hline \multicolumn{6}{|c|}{ Anxiety (\%) } \\
\hline Minimal & $2(9.1)$ & 8 (21.6) & $10(16.9)$ & \multirow{3}{*}{$X^{2}: 7.892$} & \multirow{3}{*}{0.019} \\
\hline Mild & $9(40.9)$ & $23(62.2)$ & $32(54.2)$ & & \\
\hline Severe & $11(50)$ & $6(16.2)$ & $17(28.8)$ & & \\
\hline
\end{tabular}

symptoms are triggered by specific sounds, and to elude them, the patient has to use several coping mechanisms, ranging from leaving the scene, suppressing the triggering sound if it cannot be moved away, acting incompatible with the current situation, or warning the sound source. These behavioral patterns, combined with the patient's anxiety, adversely affect the quality of daily life.

Schröder et al. (9) accepted misophonia as a new psychiatric disorder and proposed the first set of diagnostic criteria in 2013. Dozier et al. (14) stated that there was not enough data to conclude that it was a psychiatric disease, and came up with a new set of diagnostic criteria indicating that misophonic stimulus could arise from any source (human, animal, electrical equipment). It has also been suggested that although auditory and visual stimuli are the most common, any other stimulus may also trigger misophonia (14). Misophonia is not classified in the Diagnostic and Statistical Manual of Mental Disorders, Fifth Edition or in the International Classification of Diseases Eleventh Edition. Unlike earlier suggestions, the current opinion is that misophonia is a distinct disorder on its own, rather than a symptom of another disease or a part of the hyperacusis spectrum with psychiatric comorbidity $(8,15)$.

Although studies have shown that sounds and images can provoke misophonia, the sensitivity to sounds is at the forefront. The exact meaning of misophonia might cause confusion. Misophonia has selective sound sensitivity, which means it is not triggered by all sounds. In our study, the most common triggers were lip-smacking and throat sounds. One of the patients was a nurse and described the monitor sounds in the intensive care unit as a misophonic trigger.

Schröder et al. (16), who employed electroencephalography and oddball paradigms, compared auditory event-related potentials between misophonic patients and controls and reported that early attention and detection of sensory changes were disrupted in misophonia.

Although misophonia may coexist with tinnitus and hyperacusis, this is not an inseparable association (17). Misophonia can be seen in people with normal hearing (13). There are also reported cases of misophonia with hearing loss (18).

The anterior cingulate cortex is involved in the perception of sensory stimuli and the processing of emotions. A comprehensive functional MRI study on brain structural measurements of misophonic patients showed increased myelinization in the ventromedial prefrontal cortex (19). Triggers are associated with abnormal functional communication between the anterior insular cortex and the ventromedial prefrontal cortex, posteromedial cortex, hippocampus, and amygdala in misophonic patients. The anterior insular cortex is responsible for increased heart rate and galvanic skin responses in misophonic people when exposed to triggers.

The possible responsible structures mentioned above were also studied in MS and depression, and alterations in connectivity patterns between the dorsolateral prefrontal cortex, amygdala, and hippocampus were associated with higher depression scores (2). The alterations in common neurobiological pathways lead to the assumption that misophonia is likely to be the other common neuropsychiatric disorder in the MS population. Our results showed that misophonia was more common in patients with MS than the control group, which was consistent with the aforementioned hypothesis. Besides, the severity of both depression and anxiety was significantly higher in the MS group.

A 2019 study evaluating misophonia and accompanying psychiatric symptoms reported that the most common accompanying symptoms were post-traumatic stress disorder (PTSD), obsessive-compulsive disorder (OCD), major depressive disorder, and anorexia (20). A large-scale study conducted by Jager et al. (21) on 575 misophonic patients reported OCD, mood disorder and attention deficit as the most common comorbidities (26\%, $10 \%$ and $5 \%$, respectively). The intensity of anxiety is positively correlated with the severity of misophonia (7). However, we could not find such a correlation in our study. Nevertheless, a significant positive correlation was achieved only between the misophonia score and BDS score.

Functional MRI study of Schröder et al. (6) suggested a lack of activity in the amygdala when fear levels were not increased on the behavioral data. This finding concurs well with the idea that anxiety is not a primary feeling but can develop over time, as expected (6).

To date, depression and anxiety were well defined in patients with MS, although none explored the misophonia effect on those. In our study, the presence of misophonia in the MS group increased $\mathrm{BDI}$ and BAI scores. 
Individualized therapy is mandatory on grounds of a variety of sources of misophonia triggers, and every manifestation of misophonia cannot be treated by a single therapy approach. As yet, there's no proven pharmacological treatment of misophonia, nonetheless, case reports and anecdotal information recommend use of antidepressants and anxiolytics for comorbid psychiatric conditions $(22,23,24)$. Other treatment aspects include tinnitus retraining therapy designed by Jastreboff and Jastreboff (25) to manage tinnitus and secondarily hyperacusis and misophonia. Several studies have suggested cognitive behavioral therapy $(26,27)$. Other proposed treatment strategies are counterconditioning treatment (28), mindfulness and acceptance (29), and dialectical behavior therapy (30). A recent large-scale study by Claiborn et al. (31) reported that most participants did not receive treatment for their misophonia, and of those who did, the results were generally disappointing, with $57 \%$ reporting no improvement and $7 \%$ reporting worsening. Alcohol is shown to be a relieving factor, whereas caffeine has the opposite effect (32). It is crucial to keep in mind that these assessments are results of early observations, and there is a need for large scale studies to suggest evidence-based treatment modalities.

One of the critical limitations of this study was the small sample size. Secondly, the A-miso-S scale was used to investigate the severity of misophonia; since it was not validated in the Turkish population, data might be subjective due to the lack of empirical standards to test misophonia and its severity. Thirdly, no comments could be made about the presence of hearing loss, hyperacusis or tinnitus, since hearing tests could not be performed on patients yet none of the participants described a history with hearing problems. Measure of depression was made by using depression self-ratings and a structured clinical interview were lacking, therefore, common comorbid psychiatric diseases, including OCB, PTSD, and eating disorders could not be evaluated.

Our study wanted to show that misophonia might be common in patients with MS and evaluate its effect on depression and anxiety. Therefore, we interpreted the possible anatomical relationship between these two diseases, inspired by the literature. Although not all of the MRI of the patients included in the study could be accessed, we think that future studies involving larger patient groups and MRI correlations will help to evaluate the anatomical relationship.

The frequency of misophonia in patients with MS has remained unexplored until today. Our study is the first study on this subject. Therefore, there is no information in the literature about the relationship between misophonia and depression in patients with MS. Our study reveals the presence of an increased depression score in MSwM and a positive correlation between depression score and misophonia score. However, since our current study is a crosssectional study, it is insufficient to answer whether depression is increasing misophonia, misophonia is increasing depression, or both are increasing in a vicious circle. A longitudinal cohort study of patients with depressive MS and treatment for depression is required to elucidate these relationships fully. The analysis of this study will contribute to examining how it affects the presence or score of misophonia in patients with MS receiving effective depression treatment.

\section{Conclusion}

We investigated the relationship between MS and misophonia and found an increased prevalence of misophonia. Our results were consistent with the literature in terms of MS-induced depression and anxiety. Patients with MS are vulnerable in multiple aspects, and misophonia should be kept in mind in patients who suffer from depression and anxiety. Proper evaluation and treatment recommendations about misophonia can increase the quality of life in patients with MS.

\section{Ethics}

Ethics Committee Approval: Ankara City Hospital Institutional Review Board/Ethics Committee approved the study protocol (protocol number: E1-20-1315).

Informed Consent: Informed consent forms were obtained from all patients and controls.

Peer-review: Externally peer-reviewed.

\section{Authorship Contributions}

Concept: S.G.K., H.Y., S.M., Design: S.G.K., H.Y., N.K.Ş., Data Collection or Processing: S.G.K., H.Y., N.K.Ş., Analysis or Interpretation: S.G.K., H.Y., N.K.Ş., Literature Search: S.G.K., N.K.Ş., Writing: S.G.K.

Conflict of Interest: No conflict of interest was declared by the authors.

Financial Disclosure: The authors declared that this study received no financial support.

\section{References}

1. Wang FM, Davis MF, Briggs FB. Predicting self-reported depression after the onset of multiple sclerosis using genetic and non-genetic factors. Mult Scler 2021;27:603-612.

2. Riccelli R, Passamonti L, Cerasa A, et al. Individual differences in depression are associated with abnormal function of the limbic system in multiple sclerosis patients. Mult Scler 2016;22:1094-1105.

3. McKay KA, Tremlett H, Fisk JD, et al. Psychiatric comorbidity is associated with disability progression in multiple sclerosis. Neurology 2018;90:e1316-e1323.

4. Wu MS, Lewin AB, Murphy TK, Storch EA. Misophonia: incidence, phenomenology, and clinical correlates in an undergraduate student sample. J Clin Psychol 2014;70:994-1007.

5. Zhou X, Wu MS, Storch EA. Misophonia symptoms among Chinese university students: incidence, associated impairment, and clinical correlates. Journal of Obsessive-Compulsive and Related Disorders 2017;14:7-12.

6. Schröder A, van Wingen G, Eijsker N, et al. Misophonia is associated with altered brain activity in the auditory cortex and salience network. Sci Rep. 2019;9:7542

7. Siepsiak M, Sobczak AM, Bohaterewicz B, Cichocki, Dragan W . Prevalence of misophonia and correlates of its symptoms among inpatients with depression. Int J Environ Res Public Health 2020;17:5464.

8. Rouw R, Erfanian M. A large-scale study of misophonia. J Clin Psychol 2018;74:453-479.

9. Schröder A, Vulink N, Denys D. Misophonia: diagnostic criteria for a new psychiatric disorder. PLoS One 2013;8:e54706.

10. Binzer S, McKay KA, Brenner P, Hillert J, Manouchehrinia A. Disability worsening among persons with multiple sclerosis and depression: A Swedish cohort study. Neurology 2019;93:e2216-e2223.

11. Wood B, Van Der Mei IA, Ponsonby AL, et al. Prevalence and concurrence of anxiety, depression and fatigue over time in multiple sclerosis. Mult Scler 2013;19:217-224.

12. Théaudin $\mathbf{M}$, Romero $\mathrm{K}$, Feinstein A. In multiple sclerosis anxiety, not depression, is related to gender. Mult Scler 2016;22:239-244.

13. Jastreboff MM, Jastreboff PJ. Decreased sound tolerance and tinnitus retraining therapy (TRT). The Australian and New Zealand Journal of Audiology 2002;24:74-84.

14. Dozier TH, Lopez M, Pearson C. Proposed diagnostic criteria for misophonia: A multisensory conditioned aversive reflex disorder. Front in Psychol 2017;8:1975. 
15. McKay D, Kim SK, Mancusi L, Storch EA, Spankovich C. Profile analysis of psychological symptoms associated with misophonia: a community sample. Behav Ther 2018;49:286-294.

16. Schröder A, van Diepen R, Mazaheri A, et al. Diminished n1 auditory evoked potentials to oddball stimuli in misophonia patients. Front Behav Neurosci 2014;8:123.

17. Duddy DF, Oeding KA. Misophonia: an overview. Seminars in hearing. Thieme Medical Publishers 2014:084-091.

18. Jastreboff PJ, Jastreboff MM. Decreased sound tolerance: hyperacusis, misophonia, diplacousis, and polyacousis. Handb Clin Neurol 2015;129:375-387.

19. Kumar S, Tansley-Hancock O, Sedley W, et al. The brain basis for misophonia. Curr Biol 2017;27:527-533.

20. Erfanian M, Kartsonaki C, Keshavarz A. Misophonia and comorbid psychiatric symptoms: a preliminary study of clinical findings. Nord J Psychiatry 2019;73:219-228.

21. Jager I, de Koning P, Bost T, Denys D, Vulink N. Misophonia phenomenology, comorbidity and demographics in a large sample. PloS One 2020;15:e0231390.

22. McGuire JF, Wu MS, Storch EA. Cognitive-behavioral therapy for 2 youths with misophonia. J Clin Psychiatry 2015;76:573-574.

23. Tunç S, Başbuğ HS. An extreme physical reaction in misophonia: stop smacking your mouth! Psychiatry and Clinical Psychopharmacology 2017;27:416-418.

24. Vidal C, Vidal LM, Lage MJA. Misophonia: case report. European Psychiatry 2017;41(Suppl 1):S583-S644.
25. Jastreboff PJ, Jastreboff MM. Tinnitus retraining therapy: a different view on tinnitus. ORL J Otorhinolaryngol Relat Spec 2006;68:23-29.

26. Jager IJ, Vulink NNC, Bergfeld IO, van Loon AJJM, Denys DAJP. Cognitive behavioral therapy for misophonia: A randomized clinical trial. Depress Anxiety 2020;38:708-718.

27. Zimmerman M, Martinez JA, Attiullah N, et al. Why do some depressed outpatients who are in remission according to the Hamilton Depression Rating Scale not consider themselves to be in remission? J Clin Psychiatry 2012;73:790-795.

28. Dozier TH. Counterconditioning treatment for misophonia. Clinical Case Studies 2015;14:374-387.

29. Schneider RL, Arch JJ. Case study: a novel application of mindfulness-and acceptance-based components to treat misophonia. Journal of Contextual Behavioral Science 2017;6:221-225.

30. Kamody RC, Del Conte GS. Using dialectical behavior therapy to treat misophonia in adolescence. Prim Care Companion for CNS Disord 2017;19:17102105.

31. Claiborn JM, Dozier TH, Hart SL, Lee J. Self-identified misophonia phenomenology, impact and clinical correlates. Psychological Thought 2020;13:349-375.

32. Edelstein M, Brang D, Rouw R, Ramachandran VS. Misophonia: physiological investigations and case descriptions. Front Hum Neurosci 2013;7:296. 